\section{A CASE OF \\ LUPUS OF SEVEN YEARS' STANDING SUC- CESSFULLY TREATED BY LARGE DOSES OF IODIDE OF POTASSIUM.}

\author{
BY ROBERT MUNRO, M.A., M.D.
}

IN the summary given in THs LANCET for Dec. 30th, 1871, of the medical events of the year, I find the following remarks:- "Iodide of potassium is doing wonders in the cure of diseases probably syphilitic; though, as Dr. Buzzard suggests, we are perhaps reasoning in a circle in setting down all diseases cured by iodide of potassium as syphilitic. The size of the doses taken, and apparently required, for the therapeutic effect is a very anti-infinitesimal sort of fact. Mr. Gay is curing a lupus of twenty years' standing with half-drachm doses three times a day, and Dr. Moxon and Dr. Anstie lately reported remarkable cases of syphilitic disease of the nervous system cured respectively by scruple doses and ten-grain doses three times a day." A description of the case of lupus here referred to will be found in THE LANCET for Dec. 9th, 1871, and Feb. 24th, 1872. Being somewhat interested in the effects of large doses of iodide of potassium, and happening to be in London for a few weeks while this case was under treatment, I had an opportunity, through the kindness of Mr. Gay, of seeing his patient. The cicatrisation was then nearly completed, and altogether the results of this drug appeared to me so eminently satisfactory that $\mathrm{I}$ resolved to try it on the first suitable opportunity. With the above facts already before the profession, I think the following case is worthy of being recorded, inasmuch as it is an additional evidence of the great value of iodide of potassium as a therapeutic agent in a class of diseases that have almost become an opprobrium to the healing art.

S. S- a strong, muscular man, of a ruddy complexion, and twenty-seven years of age, consulted me about the middle of May, 1872, in regard to a lupus in his nose and face. The disease was of seven years' standing, and, besides involving the nose, the upper lip, the mucous membrane of the nostrils, and rather wore than a square inch of the roof of his mouth, it extended in an irregular patch for about two inches down both cheeks. There was a slight but offensive discharge from the ulcerations, and his breath had a fetid odour, which I thought proceeded from the ulcerated roof of his mouth. He was dispirited about his case, as he had already consulted many of the most noted surgeons in this vicinity and in Glasgow without benefit. From a written account which he gave me of his own case, I could not gather much information in regard to his past treatment. Six years ago an eminent surgeon here recommended him to have the diseased portion removed by the knife, but this he declined. A distinguished professor recommended some ointment, which, he says, had no effect whatever on his face. Others told him it was cancer, and incurable. Latterly he fell into the hands of quacks, and had a plaster (probably arsenical) applied to the sore. In concluding his report he says: "I returned to Dr. - again, as I did time after time, as a fox to his hole for safety." No syphilitic history could be elicited. About a year ago I saw a woman here with psoriasis guttata, who had been taking arsenic for nearly twelve months without any kenefit, except irritation of her eyes, but in a few weeks she got better under the internal administration of carbolic acid. This woman now turns out to be a sister of my patient with lupus. The patient also tells me that his father at certain seasons of the year had spots on his legs and arms similar to those $I$ had seen on his sister. Thus psoriasis seems to have been in the family.

I at once commenced the treatment of the lupus by giving ten-grain doses of the iodide of potassium three times a day. On one cheek the disease was attached to the nose only by a narrow isthmus; and, wishing to observe the effect of a caustic on the sore, I brushed over the whole of this nearly isolated portion on the cheek by the acid nitrate of mercury. The crust dropped off in a few days, and left the sore with a much more healthy appearance. I then, at intervals of about a week, touched other portions of the disease with this caustic, until at the end of six weeks I had gone over the whole of the surface of the disease, so far as it manifested itself externally. Each crust was removed by poultices, and the sores then dressed with the following Jotion:-Carbolic acid, three drachms; sulphate of zinc, eighteen grains; water, twelve ounces.

About three weeks after the treatment was commenced I increased the iodide of potassium to one-scruple doses three times a day, and added three drops of the liquor arsenicalis to each dose. The progress of the case was very satisfactory; and about the beginning of August the patient's face was completely skinned over, and since then it has remained perfectly well.

I showed this case to various medical men, who all expressed themselves as highly pleased with the result; and on the 23rd of August to Mr. Gay, who happened to be in the neighbourhood, and who gave a highly favourable opinion as to the permanency of the cure. $\mathrm{Up}$ to this date (Sept. 16th) the cicatrices are becoming more of the colour of the skin, and there is not anywhere the slightest appearance of a recurrence of the disease.

Observations.- The post hoc propter hoc in the above case may appear somewhat doubtful, but for the following reasons I am of opinion that the iodide of potassium was the curative agent:-

1. The roof of the mouth and nucous membrane of the nostrils began to improve at an early stage, and ultimately became quite healthy, although no external treatment was used.

2. I am led to believe that arsenic was previously repeatedly tried in the case without any benefit; besides the small quantity used on the present occasion could hardly have the effect.

I have no doubt the acid nitrate of mercury assisted the favourable action of the iodide of potassium, by correcting morbid action in the sores. A few weeks after the patient commenced to take scruple doses of the iodide of potassium some red papular spots appeared on his neck, head, and body, but they did not cause any annoyance. Otherwise $I$ have not observed any constitutional effects from the use of this drug, though it was administered for nearly three months.

Kilmarnock, X.B.

\section{UTERO-PERITONEAL FISTULA.}

\section{BY LAWSON TAIT, F.R.C.S.}

IT is somewhat singular that, in the short time which has elapsed since the publication of my last case, I should have had two other cases of this singular condition under my care at the Hospital for Women. We know so little about it at present that I shall content myself with merely narrating the cases, reserving my comments until my experience shall have grown.

Lucy $\mathrm{K}-$ - aged twenty-six, applied at the hospital on March 22nd. She is the mother of four children, the last having been born five months previous to my seeing her. Since that confinement she has menstruated profusely, every month, for eight or nine days. The cervix was open, and, as I regarded the case as one of ordinary sub-involution, I passed the sound, on her second visit (April 5th). The sound passed straight up to the umbilicus without a hitch, and could be made apparent under the abdominal walls at almost any point. The uterus could not be felt above the pubis, and between the hands it felt very little larger than normal. The sound seemed to emerge from the middle of the fundus. The cervix was in a peculiar granular condition, and little pieces could be picked off by the nail, conveying a feeling to the finger, not of malignant disease, but of something with which I have not met before. Under bromide of potash she improved so that in April she menstruated only five days and not profusely. I sav her last on June 21st, when she was menstruating in normal quantity.

Sarah S-, aged thirty-three, has been married for seven years, and is the mother of four children. The last was born twelve months previous to her first visit to the hospital, and on that occasion her confinement was of longer duration than usual, her recovery was slow, and ever since 
she has had a profuse purulent discharge. The uterus is fixed, and a firm immovable mass occupies the whole of the pelvis, being felt all round the uterus, in the bladder and in the rectum. The cervix is retracted, and the os feels only like a pimple, though quite open. I cannot give any reason for my suspicion, but before $I$ passed the sound I entertained the belief that in this case it would pass into the peritoneal cavity, and the extreme care with which I introduced the sound was remarked by our resident medical officer, Mrs. Louisa Atkins. The sound passed straight up to the neighbourhood of the umbilicus, and was there felt under the integuments, and its point could be made to travel freely about. I have repeatedly passed the sound in this case into the peritoneal cavity, and I find it always goes in one particular track, and in that direction no exertion whatever is needed to pass it. I passed it this morning (Oct. 5th) in presence of my colleagues, and they had no doubt of the existence of a fistulous track.

Two explanations of this case have offered themselves to me. The first was that it might be a case of encephaloid cancer, the fundus uteri or part of it having been destroyed by ulceration. The alternative was that it was a case of suppurating hæmatocele, which had burst in two directions and left a fistula. To this latter view the progress of the case has driven me, and I am glad to find that my colleagues support me in it. The feeling of the tumour is not that of so large an extension of malignant disease. It has not interfered with neighbouring organs. The discharge is purulent, though on microscopic examination some epithelial-looking cells have proliferated nuclei which are suspicious; and the patient does not look cachectic. Moreover, she is improving under treatment. An interesting point in this case is that almost certainly a large amount of purulent fluid has found and does now find its way into the peritoneal cavity without doing any apparent injury.

In neither of these cases does the passing of the sound give rise to pain or trouble of any kind.

Great Charles-street, Birmingham.

\section{ON THE}

\section{VALUE OF THE HYDRATE OF CROTON CHLORAL IN PAINFUL AFFECTIONS OF THE FIFTH NERVE.}

\section{BY J. WICKHA IT LGG, M.D.}

CASUALTX PHYSICIAN TO ST. BARTHOLOMEW'S HOSPITAL.

IT is perhaps surprising that a remedy whose action was several months ago declared to be of so extraordinary a character should have received so little attention at the hands of the profession, especially when this new medicine promised to be so efficient a weapon against some of the most painful diseases known to physicians. Beyond one or two pharmacological notices, the substance seems to have been altogether passed by.

The hydrate of croton chloral was made by Krämer and Pinner, by the action of alkalies upon dichlorallyl and formic acid. Its physiological action was investigated by o. Liebreich. He found that in animals it produced a deep anæsthesia of the head, without any loss of sensibility of the body. Death was caused by a paralysis of the medulla oblongata. In man, an anæsthesia of the fifth only was noticed. The sensibility of the trunk, and the pulse and respiration, remained unaltered.

Having procured some of this substance, I determined to make observations upon such of my patients at St. Bartholomew's as appeared likely to be benefited by the use of the medicine. I gave it to about twenty persons, nearly all women. They varied in age from seventeen to fortyfour. They were all suffering pains in the regions supplied by the fifth nerve-that is, the upper and lower jaw, the face, and the supra-orbital region of the forehead. The pains were paroxysmal. In the majority of the cases they were increased at night. In nearly every one of these cases there was caries of the teeth. In about half there were signs of anæmia. The medicine was given in doses of five, ten, and twenty grains, dissolved in water. It was given at night, just before going to bed. In one case, where the pains became aggravated at noon and at bedtime, it was given just before the increase of pain was expected. In all the patients, except two, great relief from pain followed the dose of croton chloral. Some of the patients sajd that they slept well after it; others, that they did not sleep, but that the pains in the head and face either ceased altogether, or were much diminished. In two cases, both women, the croton chloral was of no use whatever, the pains being agrravated during the use of the medicine; but in the rest of the cases more or less relief was given.

Should the croton chloral be as efficient in the hands of others as it has been in mine, it will prove a most important addition to the Materia Medica. It will enable the physician to give relief from pain until relief can be afforded by the dentist, or by attention to the general health, and this without any of the general effects of narcotics. It is almost unnecessary to dwell further upon the advantage of possessing such a means.

I may conclude by stating that Messrs. Evans and Leschner, of Bartholomew-close, keep the hydrate of croton chloral in stock.

Green-street, Park-lane.

\section{HYDROCELE OF THE SEMINAL VESICLE.}

\section{Br N. R. SMITH, M.D.}

Diseases of the seminal vesicles have received very little attention from pathologists, probably because of their obscurity and infrequent occurrence. There is an excellent but brief, article on this subject in Holmes's System of Surgery, by George M. Humphry, but he does not mention the affection which $I$ am about to describe, nor have $I$ noticed it in any other author. The seminal vesicle is wrapped in an envelope similar to that of the ovary, and is cellular in structure. We should not be surprised, therefore, to find it similarly affected in disease.

Some twelve years since I was called to a case (in consultation with Dr. B-, of the city of Baltimore), represented to be one of retention of urine. I found a large pyriform tumour occupying the cavity of the pelvis, and also that of the abdomen, higher than the umbilicus. There was no gaseous resonance over any part of it, but when percussed it sounded and vibrated like a fluid in a tensely distended sac. The patient was passing, every hour, half an ounce of urine perfectly normal in character. The at tending physician assured me that he had repeatedly in troduced the catheter into the bladder and had drawn not more than an ounce of urine; not in the least reducing the volume of the tumour.

Still 1 bad not the slightest doubt that I was dealing with a distended bladder. All surgeons are aware that when the bladder becomes greatly distended it ascends into the cavity of the abdomen, the prostatic and mem branous portions of the urethra becoming retracted and elongated, so that an ordinary catheter may be introduced its whole length, and its point not pass the uvula of the bladder, and no urine flow. The fact that urine was dribbling away involuntarily, from time to time, is also well known to be a common occurrence when the bladder is distended.

I had had not long before committed to my care from the country a gentleman who had been suffering from distended bladder. His country pbysician wrote me that he had repeatedly introduced a catheter fairly into the bladder and not a drop of urine had flowed. He was quite indignant at my opinion that the bladder had not been reached, and equally astonished when $I$ introduced a long and large catheter and drew of some five pints of turbid urine.

In the present case, then, I had at first no doubt that I should ind the bladder distended. I was greatly surprised, then, when on introducing a long catheter fairly into the bladder there flowed only an ounce of perfectly normal urine. On placing my hand on the tumour I found it not in the least reduced in size, and, as I moved the catheter, I distinctly felt the instrument gliding about in close contact with the walls of the belly, being pressed forward by the pyriform tumour. 